* Mestrando em Direito pela Universidade Federal de Minas Gerais (UFMG).

Especialista em Direito Civil Aplicado em 2016 pela Pontifícia Universidade Católica de Minas Gerais (PUC Minas).

Graduado em Direito em 2014 pela Faculdade Milton Campos (FMC).

Email: danieldepaduaandrade@gmail.com

** Doutor em Direito em 2015 pela Universidade Federal de Minas Gerais (UFMG).

Mestre em Direito em 2010 pela Universidade de Coimbra (UC).

Graduado em Direito em 2006 pela Universidade Federal de Minas Gerais (UFMG).

Email: fabio.queiroz@gmail. com

\section{Revisitando o Papel da Violação \\ Positiva do Contrato na Teoria do \\ INADIMPLEMENTO}

\author{
Reviewing the Role of the Positive \\ BREaCH OF CONTRACT IN THE THEORY OF \\ DEFAULT
}

\section{Daniel de Pádua Andrade* Fabio Queiroz Pereira**}

Como citar: ANDRADE, Daniel de Pádua; PEREIRA, Fabio Queiroz. Revisitando o papel da violação positiva do contrato na teoria do inadimplemento. Scientia Iuris, Londrina, v. 22, n. 1, p.258-282, mar. 2018. DOI: $10.5433 / 2178-8189.2018 \mathrm{v} 22 \mathrm{n} 1 \mathrm{p} 258$. ISSN: $2178-8189$

Resumo: Atualmente, no direito brasileiro, prevalece a aplicação da violação positiva do contrato enquanto instrumento autônomo de tutela dos interesses obrigacionais indiretamente vinculados à prestação. Segundo esse entendimento majoritário, as figuras do inadimplemento absoluto e da mora restringemse aos interesses obrigacionais diretamente relacionados com a prestação. A releitura contemporânea do direito das obrigações, entretanto, revela a indissociabilidade entre deveres de proteção e deveres de prestação. A partir da reformulação conceitual do (in) 
adimplemento no ordenamento jurídico brasileiro, o presente estudo propõe a revisão do papel da violação positiva do contrato na teoria do inadimplemento. Trata-se de uma investigação de vertente jurídico-teórica e de tipo jurídicopropositivo. Vale-se, pois, de metodologia qualitativa que parte de dados secundários e se utiliza de raciocínios indutivos, buscando trabalhar bases normativas e doutrinárias para a formulação de novos enquadramentos relativos à matéria. Nesse sentido, ao invés de terceira espécie de inadimplemento, sugere-se a consideração da violação positiva do contrato como referencial teórico de atualização e ampliação dos institutos do inadimplemento absoluto e da mora.

Palavras-chave: Violação positiva do contrato. Teoria do inadimplemento. Direito das obrigações.

Abstract: Currently, in Brazilian law, the positive breach of contract is applied as an autonomous instrument to protect the obligatory interests indirectly linked to the provision. According to this majority view, the figures of absolute default and delay are restricted to the obligatory interests directly related to the provision. The contemporary re-reading of the law of obligations, however, reveals the inseparability between duties of protection and duties of provision. Based on the conceptual reformulation of default and performance in 
the Brazilian legal system, the present study proposes to review the role of positive breach of contract in the theory of default. This body of work is an investigation of the legaltheoretical aspect and of the legal-propositional type. This study uses, therefore, a qualitative methodology that, from secondary data and inductive reasoning, seeks to work normative and doctrinal bases for the formulation of new frameworks related to the matter. In this sense, instead of a third kind of default, it is suggested to consider the positive breach of contract as a theoretical reference to update and expand the institutes of absolute default and delay.

Key-words: Positive breach of contract. Theory of default. Law of obligations. 


\section{INTRODUÇÃO}

Passados mais de quinze anos da promulgação do Código Civil de 2002, ainda persistem controvérsias quanto à conformação do regime legal do inadimplemento. Embora represente aperfeiçoamento da legislação anterior, a sistematização da matéria no título IV do Livro I da Parte Especial tem sofrido críticas pontuais (MARTINS-COSTA, 2006, p. 100). Um dos questionamentos mais significativos refere-se ao desamparo legal dos interesses obrigacionais não vinculados diretamente à prestação. Nesse ponto, doutrina e jurisprudência brasileira encontraram uma alternativa na figura alemã da violação positiva do contrato. No Brasil, esta teoria tem sido utilizada como uma terceira espécie de inadimplemento, fundamentada no princípio da boa-fé objetiva e na aplicação analógica do arcabouço normativo referente às outras duas espécies (inadimplemento absoluto e mora). Não obstante as vantagens práticas dessa utilização, seu lastro elástico e indefinido evidencia o risco de insegurança jurídica e subjetivismo no caso concreto.

O objetivo do presente estudo é propor, no ordenamento jurídico brasileiro, a revisão do papel da violação positiva do contrato na teoria do inadimplemento. A releitura contemporânea do direito das obrigações revela a indissociabilidade do prestar e do resguardo dos bens jurídicos dos contratantes. Com efeito, faz-se possível alargar os institutos do inadimplemento absoluto e da mora, para que atuem não apenas como resposta jurídica para a lesão aos interesses à prestação, mas também como remédio para a inobservância dos interesses à proteção. Nesse contexto, embora continue válido o respectivo referencial teórico, tornase desnecessário o recurso à violação positiva do contrato enquanto terceira modalidade de descumprimento obrigacional. $O$ enquadramento 
ora proposto perpassa pela análise da origem e da assimilação brasileira da teoria da violação positiva do contrato, bem como pelo estudo da perspectivação dinâmica da obrigação e da reformulação conceitual do (in)adimplemento.

\section{A ORIGEM DA VIOLAÇÃO POSITIVA DO CONTRATO}

A teorização da violação positiva do contrato remonta à doutrina alemã do início do século passado ${ }^{1}$. Mais especificamente, a origem do instituto é atribuída aos estudos de Hermann Staub, que introduziu a figura da positive Vertragsverletzung em artigo publicado em 1902. O título de seu trabalho pioneiro, Die positiven Vertragsverlezungen und ihre Rechtsfolgen, pode ser traduzido para o português como "As violações positivas do contrato e suas consequências jurídicas”. Esse desenvolvimento foi fruto de críticas à disciplina legal do descumprimento contratual prevista no Bürgerliches Gesetzbuch (BGB), Código Civil da Alemanha que entrou em vigor em 1900.

$\mathrm{Na}$ esteira do Code Napoleon de 1804, o BGB regulou duas espécies de inadimplemento (SILVA, 2002, p. 7-11). O §280 estabeleceu a categoria da impossibilidade (Unmöglichkeit), enquanto o $§ 286$ definiu a categoria da mora (Verzug). Logo nos primeiros anos de vigência do Código Civil alemão, entretanto, as falhas desse tratamento dicotômico foram denunciadas por Hermann Staub. Segundo ele, várias situações de descumprimento contratual não se amoldariam à impossibilidade (entendida como a impraticabilidade superveniente da prestação não executada) ou à mora (entendida como o retardo temporal da prestação

1 Para uma exposição detalhada do histórico da violação positiva do contrato (CORDEIRO, 2015, p. 594602; SILVA, 2002, p. 1-30; STEINER, 2014, p. 199-210. 
devida $)^{2}$. Nomeadamente, haveria uma lacuna no BGB em relação aos casos em que o devedor, embora efetuasse a prestação, causasse danos ao credor. Hermann Staub denominou essas hipóteses de violações positivas do contrato e apontou como solução a aplicação analógica do regramento da mora (CORDEIRO, 2015, p. 595).

A proposta de Hermann Staub obteve rapidamente amplas repercussões no meio jurídico alemão. A jurisprudência simpatizou com a teoria, que possibilitava "uma margem oportuna de concretização no caso real, embora com o perigo, inerente a tais esquemas, de uma fuga simples para a equidade" (CORDEIRO, 2015, p. 596). A doutrina, pelo contrário, levantou diversas objeções. Nesse sentido, por exemplo, criticou-se a ausência de definição unitária do instituto e afirmou-se a inexistência da pretensa lacuna legal. Ademais, a própria terminologia do instituto sofreu questionamentos que perduram até os dias de hoje ${ }^{3}$. A crítica mais impactante, no entanto, foi elaborada por Heinrich Stoll. Este autor publicou em 1932 um provocativo texto intitulado

2 Como explica Jorge Cesa Ferreira da Silva, "[d]iversos exemplos que não poderiam ser reconduzidos às categorias da impossibilidade ou da mora para o direito alemão foram dados por STAUB. Talvez o mais interessante deles seja o do membro de uma sociedade que tinha o dever de entregar, nos primeiros três meses do ano fiscal, o balanço da empresa. Em face do balanço, disposições internas seriam adotadas, fazendo com que a sociedade tomasse este ou aquele rumo. Na segunda semana após o início do ano fiscal, o sócio apresenta balanço demonstrando que a situação da empresa era muito boa. Contudo, 14 dias mais tarde, evidencia-se que dito balanço fora produzido com extrema negligência, e que por isso, o conteúdo do documento não refletia a realidade. As decisões, baseadas no errôneo balanço e tomadas ao longo desses 14 dias, geraram danos à empresa. Nesse momento, entrega o sócio à empresa o balanço verdadeiro. Poder-se-ia considerar este um exemplo de impossibilidade da prestação? A resposta de STAUB é negativa, dado que a entrega do verdadeiro balanço ainda era possível, tanto que o sócio o fez posteriormente. De outra parte, igualmente não houve qualquer atraso na prestação, na medida em que os dois balanços foram entregues durante o prazo inicialmente estabelecido ( 3 meses). O problema todo decorreu do fato de que o conteúdo do documento que o sócio forneceu era falso e não da sua não-entrega ou do atraso na sua entrega. Ou seja, o problema adveio de uma atividade positiva" (SILVA, 2002, p. 13-14).

3 Segundo Jorge Cesa Ferreira da Silva, "[c] ostuma-se afirmar que tanto o substantivo "contrato" como o adjetivo "positiva" estariam mal escolhidos. Tais casos de inadimplemento poderiam ser encontrados tanto nos contratos como também em outras fontes obrigacionais, como os negócios jurídicos unilaterais. Por outro lado, existem casos de deveres laterais que consubstanciam nitidamente deveres positivos, como ocorre com os deveres de informação, de sorte que o descumprimento desses deveres, ensejadores de violações positivas do contrato, configurariam violações em realidade negativas" (SILVA, 2002, p. 16). 
"Adeus à doutrina da violação positiva do contrato" (Abschied von der Lehre von der positiven Vertragsverletzung). Neste trabalho, Heinrich Stoll sugeriu a ampliação do conceito de obrigação. Para ele, o vínculo obrigacional compreenderia tanto deveres voltados ao cumprimento da prestação (interesses de prestação) quanto deveres orientados para a preservação dos bens dos contratantes (interesses de proteção). Dessa forma, não apenas a violação dos deveres de prestação, mas também a contrariedade aos deveres de proteção acarretaria impossibilidade ou mora. Com efeito, a partir dessa perspectiva alargada, seria desnecessário o recurso à violação positiva do contrato ${ }^{4}$.

Ironicamente, a crítica de Heinrich Stoll foi utilizada para reafirmar e aclarar a teoria da violação positiva do contrato. A doutrina subsequente valeu-se da divisão entre interesses de prestação e interesses de proteção justamente para definir o campo de incidência da violação positiva do contrato. Desde então, desenvolveu-se o entendimento de que o descumprimento de deveres de prestação acarreta impossibilidade ou mora, enquanto a inobservância de deveres de proteção implica violação positiva do contrato. Como assinala Jorge Cesa Ferreira da Silva:

A crítica de STOLL foi, não resta qualquer dúvida, profunda, mas teve conseqüência, no mínimo, inusitada para o crítico. Ocorre que, como já indicado, esse artigo

4 Nas palavras de Menezes Cordeiro: "Em aprofundamento importante, Hr. Stoll distingue, na obrigação, um interesse de prestação e um interesse de protecção. Ao serviço do primeiro, resultam deveres do contrato, a interpretar e a complementar segundo a boa fé, que tutela a obtenção efectiva do fim visado pela prestação. O segundo, por via, também da boa fé, assenta no seguinte. Havendo entre as partes uma ligação obrigacional, gera-se, com naturalidade, uma relação de confiança na base da qual é, em especial, possível o infligir mútuo de danos; a boa fé comina deveres de não o fazer. Esta análise permite constatar a presença na obrigação, de deveres de cumprimento, que visa o prosseguir efectivo do interesse do credor na prestação e de deveres de proteç̧ão que pretendem obstar a que, a coberto da confiança gerada pela existência de uma obrigação, se produzam danos na esfera das partes. Conduzindo esta consideração analítica até ao seu extremo, Hr. Stoll nega, com certa facilidade, a autonomia da violação positiva do contrato, como terceira categoria de prevaricações obrigacionais, junto da mora e da impossibilitação do dever de prestar: independentizados os deveres de cumprimento e de prestação, assistir-se-ia seja à mora, seja à impossibilidade, no seu cumprimento" (CORDEIRO, 2015, p. 598-599). 
de Stoll foi decisivo para uma melhor compreensão e organização dogmática dos chamados deveres laterais decorrentes da relação obrigacional, deveres que compõem exatamente o espectro de aplicação da doutrina da violação positiva do contrato. Desta forma, a crítica ajudou a confirmar a doutrina, e o "adeus" pretendido mais serviu para sedimentar o já declarado "Wilkommen" (SILVA, 2002, p. 19-20).

Apesar das objeções doutrinárias, a teoria da violação positiva do contrato consolidou-se na Alemanha. Atualmente, o problema diagnosticado por Hermann Staub mantém sua relevância, embora com novos contornos e controvérsias. Na Reforma do BGB de 2002, por exemplo, a violação positiva do contrato reverberou na inclusão da figura genérica da "quebra de deveres" no §280, I (STEINER, 2014, p. 200). O desenvolvimento da violação positiva do contrato irradiou para diversos ordenamentos jurídicos de civil law, dentre os quais destaca-se o direito brasileiro.

\section{A ASSIMILAÇÃO BRASILEIRA DA VIOLAÇÃO POSITIVA DO CONTRATO}

O Brasil conta hoje com farta bibliografia sobre a violação positiva do contrato ${ }^{5}$. Aqui, destaca-se o trabalho de Jorge Cesa Ferreira da Silva, que em 2002 publicou o livro "A boa-fé e a violação positiva do contrato". Tal qual ocorrera na Alemanha com o aparecimento do BGB, o advento do novo Código Civil de 2002 impulsionou a reflexão acerca da violação positiva do contrato no ordenamento jurídico brasileiro. Insta ressaltar, contudo, que o assunto não era desconhecido pela doutrina anterior. Sob a epígrafe de "adimplemento não-satisfatório", por exemplo,

5 V.g. Cunha (2014); Gama; Araújo (2011); Haical (2010); Silva (2002); Steiner (2014). 
Pontes de Miranda, em seu "Tratado de direito privado", já fazia coro com o entendimento de Hermann Staub:

Os legisladores de todo o mundo, ao tratarem de impossibilidade e de não-adimplemento, não viam que faltava considerar-se o adimplemento, que ocorreu, porém não satisfez. O devedor não só está obrigado a prestar, mas sim a prestar de tal maneira que satisfaça. Se adimple de jeito que não baste, ou que cause dano, ou imponha despesas, satisfatoriamente não adimple. Nem se há de pensar em ser impossível a prestação: foi feita; nem em faltar o adimplemento: adimpliu-se a obrigação, ou, se não havia obrigação, adimpliu-se a dívida. [...] O devedor está obrigado pelo que resulte, em danos, do adimplemento insatisfatório, segundo os princípios que regem a constituição e a eficácia da mora [...] (MIRANDA, 1971, p. 165-166).

Obviamente, o panorama jurídico brasileiro posterior ao Código

Civil de 2002 não se confunde com a situação normativa alemã pós-BGB.

No Brasil, a tutela legal do inadimplemento se mostrou mais abrangente do que as rígidas categorias da impossibilidade e da mora originalmente previstas na Alemanha. Em linhas gerais, o novo Código Civil também optou por um tratamento dicotômico. De um lado, estabeleceu-se a mora para o caso do devedor que não efetua o pagamento no tempo, lugar e forma devidos (art. 3946). De outro lado, estipulou-se o inadimplemento absoluto para a hipótese em que o descumprimento obrigacional torna a prestação inútil para o credor (art. 3897 c/c art. 395, parágrafo único ${ }^{8}$,

6 Art. 394. Considera-se em mora o devedor que não efetuar o pagamento e o credor que não quiser recebêlo no tempo, lugar e forma que a lei ou a convenção estabelecer (BRASIL, 2002).

7 Art. 389. Não cumprida a obrigação, responde o devedor por perdas e danos, mais juros e atualização monetária segundo índices oficiais regularmente estabelecidos, e honorários de advogado (BRASIL, 2002).

8 Art. 395. Responde o devedor pelos prejuízos a que sua mora der causa, mais juros, atualização dos valores monetários segundo índices oficiais regularmente estabelecidos, e honorários de advogado. Parágrafo único. Se a prestação, devido à mora, se tornar inútil ao credor, este poderá enjeitá-la, e exigir a satisfação das perdas e danos (BRASIL, 2002). 
contrario sensu). Para além dessa bipartição, contudo, a legislação civil regulou uma série de vícios gerais ${ }^{9}$ e específicos ${ }^{10}$ que tangenciam o inadimplemento.

A amplitude da regulação do inadimplemento, entretanto, não impediu que a doutrina brasileira reconhecesse a utilidade residual da violação positiva do contrato na tutela dos deveres obrigacionais de proteção. Na definição de Jorge Cesa Ferreira da Silva, a violação positiva do contrato deve ser entendida no Brasil "como todo inadimplemento decorrente do descumprimento culposo de dever lateral, quando este dever não tenha uma vinculação direta com os interesses do credor na prestação" (SILVA, 2002, p. 272-273). No mesmo sentido, embora com pequenas variações na formulação, encontram-se as lições de Judith Martins-Costa ${ }^{11}$, Carlos Roberto Gonçalves ${ }^{12}$, Gustavo Luís da Cruz Haica $1^{13}$ e Cristiano Chaves de Farias com Nelson Rosenvald ${ }^{14}$. Ademais,

9 V.g. os vícios redibitórios (arts. 441 a 446) e a evicção (arts. 447 a 457).

10 V.g. no contrato de empreitada (art. 618) e no contrato de transporte (art. 754).

11 Para Judith Martins-Costa, "[q]uem iguala ou confunde os interesses à prestação (inclusivos da obrigação principal, dos deveres secundários e dos anexos) com os interesses à proteção, tenderá a considerar que a figura da violação positiva do contrato é inútil entre nós, pois o conceito de mora no Direito brasileiro é amplo (Código Civil, art. 394), englobando tempo, lugar e modo da prestação. Essa posição é equivocada, pois tempo, lugar e modo atinem à prestação (interesses à prestação), sejam principais, secundários ou anexos, e não diretamente aos interesses à proteção («deveres laterais»). É a violação desses interesses que é apanhada pela noção de «violação positiva do contrato»" (MARTINS-COSTA, 2015, p. 690).

12 Na explicação de Carlos Roberto Gonçalves, "[a] boa-fé objetiva enseja, também, a caracterização de inadimplemento mesmo quando não haja mora ou inadimplemento absoluto do contrato. É o que a doutrina moderna denomina violação positiva da obrigação ou do contrato. Desse modo, quando o contratante deixa de cumprir alguns deveres anexos, por exemplo, esse comportamento ofende a boa-fé objetiva e, por isso, caracteriza inadimplemento do contrato. Esses deveres anexos ou secundários excedem o dever de prestação e derivam diretamente do princípio da boa-fé objetiva, tais como os deveres laterais de esclarecimento (informações sobre o uso do bem alienado, capacitações e limites), de proteção (como evitar situações de perigo), de conservação (coisa recebida para experiência), de lealdade (não exigir cumprimento de contrato com insuportável perda de equivalência entre as prestações), de cooperação (prática dos atos necessários à realização plena dos fins visados pela outra parte) etc." (GONÇALVES, 2014, p. 351).

13 Segundo Gustavo Luís da Cruz Haical, "[a] violação positiva do crédito é figura pertinente no Direito brasileiro, mas a sua aplicabilidade está centrada somente quando se der o descumprimento de deveres laterais de proteção à pessoa ou ao patrimônio do outro figurante da relação jurídica obrigacional. Esses deveres formam o interesse de proteção. Tais deveres, contudo, não estão totalmente desvinculados do interesse de prestação. Encontram-se vinculados de modo mediato" (HAICAL, 2010, p. 82).

14 Cristiano Chaves de Farias e Nelson Rosenvald entendem que "[a] lesão aos deveres genéricos de proteção, informação e cooperação repercute na chamada violação positiva do contrato. Cuida-se de uma terceira modalidade de inadimplemento das obrigações" (FARIAS; ROSENVALD, 2015, p. 516). 
na I Jornada de Direito Civil do Conselho da Justiça Federal, aprovou-se

o Enunciado 24 nos seguintes termos: "Em virtude do princípio da boafé, positivado no art. 422 do novo Código Civil, a violação dos deveres anexos constitui espécie de inadimplemento, independentemente de culpa".

A teoria da violação positiva do contrato também tem ganhado espaço nas cortes brasileiras. Atualmente, dentre os julgados dos Tribunais de Justiça Estaduais, é possível encontrar vários exemplos de aplicação do instituto. Nesse sentido, os acórdãos têm identificado violação positiva do contrato em casos como o da inobservância de deveres anexos pela operadora de plano de saúde (MINAS GERAIS, 2011), o da entrega de imóvel irregular ao adquirente (SÃO PAULO, 2017) e o da cobrança bancária em desconformidade com o dever de informar (RIO GRANDE DO SUL, 2017). Na síntese de Anderson Schreiber:

Sem embargo das suas diversas acepções, a noção de violação positiva do contrato, em seus contornos fluidos, vem sendo aplicada pelas cortes brasileiras exatamente naquelas hipóteses em que, embora se verificando um comportamento do devedor correspondente à realização da prestação contratada, não se alcança, por alguma razão, a função concretamente atribuída pelas partes à regulamentação contratual (SCHREIBER, 2007, p. 14).

Percebe-se, portanto, que a violação positiva do contrato tem se consolidado no Brasil como uma espécie autônoma de inadimplemento. Doutrina e jurisprudência utilizam essa construção para preencher uma suposta lacuna legal, ainda que restrita, relativa ao descumprimento dos deveres obrigacionais não atrelados diretamente à prestação. Esse posicionamento tem o mérito de cobrir situações não previstas 
literalmente na disciplina do inadimplemento do Código Civil de 2002. Não obstante, a elasticidade e a imprecisão da teoria evidenciam riscos de insegurança jurídica. Não existe consenso, por exemplo, sobre a necessidade de culpa para a configuração da violação positiva do contrato, tampouco sobre quais seriam as suas consequências no caso concreto. Nesse contexto, cumpre questionar se seria possível fornecer bases mais sólidas para as premissas protetivas da violação positiva do contrato. A análise dessa questão demanda uma breve digressão acerca da releitura contemporânea do direito das obrigações.

\section{A OBRIGAÇÃO SOB UMA PERSPECTIVA DINÂMICA}

Nos ordenamentos jurídicos contemporâneos, observa-se a defesa de uma percepção dinâmica do fenômeno obrigacional. Trata-se de ideia definida por contraposição à compreensão estática de obrigação, que remonta ao Corpus Iuris Civilis. As Institutas, no Título 13 do Livro III, estabeleciam que "obrigação é o vínculo jurídico ao qual nos submetemos coercitivamente, sujeitando-nos a uma prestação, segundo o direito de nossa cidade" (obligatio est iuris vinculum quo necessitate adstringimur, alicuius solvendae rei, secundum nostrae civitalis iura) (PEREIRA, C., 2017, p. 23). O conceito da obligatio romana foi resgatado na Idade Média e consagrado nas codificações oitocentistas. Essa visão estática, também chamada de clássica ou tradicional, é marcada pela leitura abstrata, estrutural e pretensamente neutra do vínculo obrigacional e centra-se em "uma noção que tem seu núcleo no poder de exigência do credor e na sujeição do devedor ao cumprimento do objeto da relação jurídica" (PEREIRA, F., 2017, p. 117).

Com o passar do tempo, esse enfoque sofreu diversas críticas 
que denunciaram sua insuficiência e artificialidade. Firmou-se a preferência por uma perspectiva dinâmica, que considere a concretude, a complexidade e a funcionalidade do programa obrigacional ${ }^{15}$. De acordo com Menezes Cordeiro, essa nova concepção "traduz a ideia de que o vínculo obrigacional abriga, no seu seio, não um simples dever de prestar simétrico a uma pretensão creditícia, mas antes vários elementos jurídicos dotados de autonomia bastante para, de um conteúdo unitário, fazerem uma unidade composta" (CORDEIRO, 2015, p. 586).

A partir de uma perspectiva dinâmica, é possível decompor a relação obrigacional em deveres de prestação (primários, secundários ou anexos), deveres de proteção, faculdades, sujeições, ônus, exceções, entre outros elementos ${ }^{16}$. Esses vários componentes da obrigação, embora distintos, encontram-se funcionalmente ordenados, polarizados no sentido do adimplemento. Como consequência, a análise da relação jurídica balizada na complexidade intraobrigacional permite compreender cada um dos elementos que compõem o vínculo, bem como o modo de conformação existente entre eles. Como sustentado por Almeida Costa, "a obrigação ou relação obrigacional como um sistema, organismo ou processo, encadeado e desdobrado em direção ao adimplemento, à

15 No mesmo sentido, Judith Martins-Costa menciona a transição de uma análise externa para uma análise interna das relações obrigacionais: "Expliquemo-nos: a análise externa, ou classificação extrínseca das relações obrigacionais, centrada no método tradicional, percebe a relação obrigacional tão-somente como um vínculo estruturado sobre dois pólos (credor e devedor), ligados pelos co-respectivos direitos e deveres. Para uma tal análise, o mais relevante é descrever os "elementos constitutivos" da relação", visualizados in abstracto: os sujeitos (credor e devedor), o objeto (a prestação, o dar, fazer ou não-fazer), os requisitos legais e os elementos acidentais, quando ocorrentes. A análise interna, diversamente, está centrada na noção de adimplemento como atuação concreta do programa obrigacional, podendo-se mesmo falar desse programa como "programa de cumprimento"” (MARTINS-COSTA, 2006, p. 4).

16 Na síntese de Menezes Leitão, "[c]onclui-se que a obrigação constitui no fundo uma relação complexa, onde se encontra algo mais que a simples decomposição dos seus elementos principais como o direito à prestação e o dever de prestar. Abrange ainda deveres acessórios, sujeições, poderes ou faculdades e excepções. Fala-se nestes casos em "relação obrigacional complexa". Através desta expressão, a doutrina faz referência ao facto de uma obrigação não poder ser recondutível estruturalmente apenas aos elementos do direito de crédito e do dever de prestação, mas incluir também um conjunto de situações jurídicas que se unem num fim que é a realização do próprio interesse do credor, sendo este o fim da obrigação" (LEITÃO, 2010, p. 126). 
satisfação do interesse credor, possibilita mais rigorosa compreensão anátomo-fisiológica do instituto e de certos dados da fenomenologia jurídica." (COSTA, 2016, p. 75).

No contexto brasileiro, deve ser destacada a importância do pensamento de Clóvis do Couto e Silva para a consagração de uma perspectiva dinâmica do fenômeno obrigacional. Em sua obra " $A$ obrigação como processo", o autor sustenta que "a relação obrigacional [...] se encadeia e se desdobra em direção ao adimplemento" (SILVA, 2006, p. 17). A satisfação do credor revela-se como ponto a dar unidade ao complexo sistema obrigacional. Para seu alcance, no entanto, podem ser visualizadas diferentes contingências que não podem ser apreciadas de maneira apartada, sem tomar em consideração a totalidade com a qual se encontram relacionadas. No curso desse processo, o autor destaca a importância da boa-fé objetiva, que vem a conformar o comportamento das partes inseridas em uma relação obrigacional (SILVA, 2006, p. 169).

A boa-fé objetiva possui papel de destaque no contexto da releitura contemporânea do direito obrigacional. Enquanto padrão social inspirado na confiança, a boa-fé objetiva deve sua sistematização à jurisprudência comercial alemã desenvolvida com base na figura dos juramentos de honra ${ }^{17}$. Hodiernamente, o princípio da boa-fé objetiva permite uma constante atualização do outrora reputado imutável direito das obrigações. No direito brasileiro, observa-se hoje uma profícua aplicação da boa-fé objetiva, lastreada principalmente nas disposições do art. $113^{18}$, do art. $187^{19}$ e do art. $422^{20}$ do Código Civil de 2002. No

17 Cf. Pereira (2013).

18 Art. 113. Os negócios jurídicos devem ser interpretados conforme a boa-fé e os usos do lugar de sua celebração (BRASIL, 2002).

19 Art. 187. Também comete ato ilícito o titular de um direito que, ao exercê-lo, excede manifestamente os limites impostos pelo seu fim econômico ou social, pela boa-fé ou pelos bons costumes (BRASIL, 2002).

20 Art. 422. Os contratantes são obrigados a guardar, assim na conclusão do contrato, como em sua execução, os princípios de probidade e boa-fé (BRASIL, 2002).

SCIENTIA IURIS, Londrina, v.22, n.1, p.258-282, mar.2018 DOI: 110.5433/2178-8189.2018v22n1p258 
entanto, tal qual verificado em outros ordenamentos jurídicos, a "autêntica paixão pelo seu potencial transformador vem ensejando invocações por vezes excessivas" (SCHREIBER, 2007, p. 4).

Dessa forma, deve-se evitar uma indesejada "mitificação" ${ }^{21}$ no tratamento dado ao princípio da boa-fé objetiva.

No direito contratual, a doutrina identifica comumente três funções operacionalizadas pela boa-fé objetiva: a função interpretativa, a função limitativa e a função integrativa ${ }^{22}$. A função interpretativa diz respeito à utilização da boa-fé como baliza hermenêutica dos negócios jurídicos. A função limitativa, por sua vez, refere-se ao uso da boa-fé objetiva no controle do exercício inadmissível de posições jurídicas. A função integrativa, por fim, tangencia a identificação de deveres obrigacionais decorrentes do standard comportamental estabelecido pela cláusula geral. Em linhas gerais, esses deveres complementam o vínculo obrigacional, sem prejuízo do exercício da autonomia negocial das partes contratantes. Não há consenso, contudo, quanto ao alcance prático e quanto à classificação desses deveres heterônomos.

No direito brasileiro, entre diversos entendimentos doutrinários, destaca-se a proposta de Judith Martins-Costa. Esta autora sistematiza os deveres obrigacionais gerados pela boa-fé objetiva em duas espécies:

21 Sobre o tema, Menezes Cordeiro pontua que "[a] boa fé sofre, na actualidade, as consequências do divórcio entre os discursos metodológicos oficiais e a dogmática jurídica. E de modo agravado: noção vaga, carregada de história, rica em implicações emotivas e objeto de utilização alargada, embora de contornos pouco conhecidos, ela presta-se, por excelência, a desenvolvimentos verbais, numa aporética dominada por uma linguagem grandiloquente e vazia de conteúdo. Há uma mitificação da boa fé" (CORDEIRO, 2015, p. 41).

22Antonio Junqueira de Azevedo associa tais funções ao direito pretoriano: "[...] a regra da boa-fé tem funções que chamo de "pretorianas" em relação ao contrato. O chamado "direito pretoriano", no direito romano, foi aquele que os pretores introduziram para ajudar, suprir, e corrigir o direito civil. Havia o direito civil estrito (direito civil mais rigoroso); o direito pretoriano veio adjuvandi, supplendi, velcorrigendi juris civilis gratia. Essa mesma tríplice função existe para a cláusula geral da boa-fé no campo contratual, porque justamente a idéia é ajudar na interpretação do contrato, adjuvandi, suprir algumas das falhas do contrato, isto é, acrescentar o que nele não está incluído, supplendi, e eventualmente corrigir alguma coisa que não é de direito no sentido de justo, corrigendi. Esse é o papel da cláusula geral de boa-fé na fase estritamente contratual" (AZEVEDO, 2017, p. 7). 
os deveres anexos e os deveres de proteção. Os deveres anexos estão instrumentalmente vinculados aos interesses de prestação. Eles atuam para otimizar o adimplemento satisfatório conforme o fim da relação obrigacional. "São deveres que não atinem ao «que» prestar, mas ao «como» prestar” (MARTINS-COSTA, 2015, p. 222). Os deveres de proteção, por outro lado, estão ligados aos interesses de preservação das partes. Seu escopo é implementar uma ordem de proteção entre as partes de forma que, "independentemente da realização da prestação, não resultem danos injustos para a contraparte" (MARTINS-COSTA, 2015, p. 224). Exemplificativamente, a necessidade de informar o comprador das qualidades da coisa vendida corporifica um dever anexo, enquanto o imperativo de sinalizar o piso molhado em um supermercado consubstancia um dever de proteção (MARTINS-COSTA, 2015, p. 223, 226).

O reconhecimento dos referidos deveres laterais ligados à boafé objetiva - independentemente do modo como são sistematizados e apresentados - tem acentuada importância na relação obrigacional vista em sua complexidade. Como assinalado, a obrigação nasce e desenvolvese no sentido do adimplemento. Nesse percurso, revela-se necessária a atenção aos deveres originados da cláusula geral, que atua na imposição de um determinado padrão de comportamento. Assim, o reconhecimento da função integrativa da boa-fé objetiva está intimamente relacionado com a ideia de totalidade ou complexidade intraobrigacional. Estas expressões definem o diagnóstico doutrinário de que a obrigação não se resume ao mero dar, fazer ou não fazer objeto da prestação. Pelo contrário, o vínculo obrigacional é composto por um amálgama de situações jurídicas ${ }^{23}$, que, por sua vez, estão permeadas pela necessária

23 Como assinala Karl Larenz, "[1]a relación de obligación, como relación jurídica concreta entre personas SCIENTIA IURIS, Londrina, v.22, n.1, p.258-282, mar.2018 DOI: 110.5433/2178-8189.2018v22n1p258 
submissão à concreção dos deveres laterais. Sobre a boa-fé objetiva e sua relação com o processo obrigacional, assinala Clóvis do Couto e Silva:

Da concreção deste princípio resultam novos deveres que não têm seu fundamento na autonomia da vontade. Implica, portanto, alterar o desenvolvimento como tradicionalmente se entendia, do processo da obrigação. Visa-se, mediante o princípio da boa-fé, instaurar uma ordem de cooperação entre os figurantes da relação jurídica. Esses deveres podem perdurar ainda depois de adimplido o crédito principal (SILVA, 2006, p. 169).

Observa-se, portanto, que o adimplemento representa hoje a confluência de interesses socialmente relevantes, que legitimam e orientam o vínculo obrigacional. A perspectivação da relação obrigacional em torno da necessidade de cumprimento de todo o programa contratual, incluídos aqui os deveres laterais adstritos à boa-fé objetiva, implica na necessidade de revisar a tutela brasileira do adimplemento e do inadimplemento. A imperiosa preservação da confiança e da cooperação entre as partes relaciona-se diretamente com o instituto da violação positiva do contrato, que, por sua vez, busca conformar os comportamentos do devedor e do credor no decurso do processo de cumprimento de uma obrigação. Importa, assim, que sejam analisados os reflexos dessa nova concepção de obrigação no âmbito do cumprimento e descumprimento da relação obrigacional.

\section{O (IN)ADIMPLEMENTO REVISITADO}

A perspectivação dinâmica da obrigação impactou 1958, p. 38). 
consideravelmente a teoria do adimplemento e, consequentemente, a teoria do inadimplemento. A compreensão clássica é centrada e restrita à prestação obrigacional. Tradicionalmente, portanto, adimplemento e inadimplemento correspondem ao cumprimento ou ao descumprimento do dar, fazer ou não fazer devido. A compreensão firmada nos últimos tempos, por outro lado, considera não apenas a efetivação da prestação, mas também o atendimento concreto aos interesses do credor, do devedor e eventualmente de terceiros.

Nas palavras de Anderson Schreiber, observa-se hoje uma tríplice transformação do adimplemento, em seus aspectos temporal, consequencial e conceitual ${ }^{24}$. Na alteração temporal, o adimplemento passa a ser considerado um processo diferido no tempo, abrangendo também o comportamento das partes contratantes antes e depois do vencimento. Essa evolução é bem ilustrada pelo instituto do inadimplemento antecipado (anticipatory breach of contract ${ }^{25}$. Quanto à modificação consequencial, afirma-se que a mera efetivação da prestação não exonera o devedor. Este poderá continuar vinculado em virtude da pós-eficácia obrigacional. Além disso, reconhece-se que a falha na prestação não autoriza por si só a resolução pelo credor. Pelo contrário, tendo em vista os princípios da conservação dos contratos e da primazia da tutela específica, deve-se primeiramente buscar remédios mais brandos que a resolução. Dessa forma, a resolução contratual deixa

24 Como explica Anderson Schreiber, “[e]xaminando sob estas novas lentes a noção de adimplemento (e, por conseguinte, de inadimplemento), identifica-se uma genuína transformação, que se pode, por razões didáticas, examinar sob três aspectos distintos: (i) temporal; (ii) conceitual; e (iii) conseqüencial. Em outras palavras, alteram-se o momento de verificação do adimplemento (tempo), as condições para sua configuração (conceito em sentido estrito) e os efeitos que dele decorrem (consequências). Em cada um destes aspectos, pode-se constatar a presença de novas figuras e construções que vêm sendo vinculadas, direta ou indiretamente, à boa-fé objetiva [...]" (SCHREIBER, 2007, p. 7).

25 Segundo Fortunato Azulay, a doutrina do anticipatory breach of contract preconiza "que, se um dos contraentes revela, por atos ou palavras peremptórias e inequívocas, a intenção de não cumprir a sua prestação, diferida a tempo certo, pode a outra parte considerar esse comportamento como inadimplência contratual" (AZULAY, 1977, p. 101). 
de ser uma faculdade do credor para consubstanciar uma ratio extrema cuja aplicação demanda justificação. Com a mudança conceitual, por fim, alteram-se as condições para a configuração do adimplemento e do inadimplemento. Ao invés de uma análise simplista do cumprimento ou descumprimento da prestação, cumpre realizar uma verificação concreta e funcional da satisfação dos legítimos interesses envolvidos. Nesse ponto, por exemplo, insere-se a figura do adimplemento substancial (substancial performance $)^{26}$.

Nesse contexto, portanto, faz-se necessária uma reformulação ampliativa da noção de adimplemento e de inadimplemento obrigacional. Hodiernamente, o adimplemento pode ser redefinido como "o cumprimento da prestação devida, presente a realização dos deveres derivados da boa-fé que se fizerem instrumentalmente necessários para o atendimento satisfatório do escopo da relação, em acordo ao seu fim e às circunstâncias concretas" (MARTINS-COSTA, 2006, p. 96). Da mesma forma, uma visão atualizada do inadimplemento deve ser construída a partir do reconhecimento da dinamicidade, da complexidade e da funcionalidade do vínculo obrigacional.

No Brasil, para compensar o anacronismo legislativo, doutrina e jurisprudência têm apostado na violação positiva do contrato. Assim, prevalece o entendimento de que o inadimplemento absoluto e a mora, tal qual previstos no Código Civil de 2002, referem-se tão somente aos interesses diretamente ligados à prestação. Nessa linha, para a tutela dos interesses vinculados apenas indiretamente à prestação, invoca-se a violação positiva do contrato com supedâneo na boa-fé objetiva. Esse

$26 \mathrm{Na}$ definição de Eduardo Luiz Bussatta, a teoria do adimplemento substancial funciona "como limite ao direito formativo extintivo à resolução dos contratos, de forma que esta somente se justifica se o inadimplemento for grave, de relevância e importância, retirando, assim, o interesse na contratação" (BUSSATTA, 2007, p. 127). 
raciocínio, não obstante suas vantagens práticas, apresenta uma distorção sistêmica. É que o inadimplemento absoluto e a mora continuam presos a uma perspectiva obrigacional estática, enquanto a violação positiva do contrato corporifica isoladamente as novas tendências do direito das obrigações. Na lição de Anderson Schreiber:

$\mathrm{Na}$ perspectiva tradicional, em que o adimplemento consiste simplesmente no cumprimento da prestação principal, a tutela do crédito em tais hipóteses exige mesmo o recurso a alguma figura ou norma externa à disciplina do adimplemento, como a violação positiva do contrato ou o (mais direto) recurso à cláusula geral de boa-fé objetiva (art. 422). Não é, todavia, o que ocorre em uma perspectiva funcional, na qual o cumprimento da prestação principal não basta à configuração do adimplemento, exigindo-se o efetivo atendimento da função concretamente perseguida pelas partes com o negócio celebrado, sem o qual todo comportamento (positivo ou negativo) do devedor mostra-se insuficiente. Vale dizer: revisitado o conceito de adimplemento, de modo a corroborar a necessidade de um exame que abarque o cumprimento da prestação contratada também sob o seu prisma funcional, as hipóteses hoje solucionadas com o uso da violação positiva do contrato tendem a recair no âmago interno da própria noção de adimplemento (SCHREIBER, 2007, p. 15).

Em outras palavras, a manutenção da violação positiva do contrato como mecanismo autônomo de tutela dos deveres de proteção perde sentido diante da constatação de que o pagamento não se resume à prestação principal. Propõe-se, portanto, a revisitação do enquadramento da violação positiva do contrato na teoria do inadimplemento. Ao invés de consubstanciar uma terceira espécie de inadimplemento, os incrementos protetivos da teoria da violação positiva do contrato podem ser assimilados pela ampliação do conceito de inadimplemento absoluto e mora para 
além da mera prestação. Destarte, o inadimplemento absoluto incluiria qualquer violação obrigacional que esvaziasse o legítimo interesse do credor, enquanto a mora abrangeria qualquer descumprimento que não afastasse por completo a utilidade da obrigação.

\section{CONCLUSÃO}

No direito brasileiro, percebe-se uma cisão entre os mecanismos de tutela dos interesses à prestação (inadimplemento absoluto e mora) e os instrumentos de preservação dos interesses à proteção (violação positiva do contrato). Sob uma perspectiva dinâmica, entretanto, a obrigação consubstancia um conjunto indissociável de deveres de prestação e deveres de proteção. Nesse contexto, apresenta maior coerência sistêmica a assimilação da violação positiva do contrato pela atualização ampliativa das tradicionais figuras do inadimplemento. Tal raciocínio é viabilizado pela maleabilidade das previsões legais do Código Civil de 2002 e pela reformulação conceitual do (in)adimplemento.

Nesse sentido, o inadimplemento absoluto pode ser revisto para abranger qualquer violação obrigacional - direta ou indiretamente vinculada à prestação - que esvazie o legítimo interesse do credor. Da mesma forma, a mora pode ser relida para alcançar qualquer descumprimento obrigacional - direta ou indiretamente vinculado à prestação - que não afaste por completo a utilidade da obrigação. Assim, ao invés de modalidade autônoma de descumprimento contratual, propõese o enquadramento da violação positiva do contrato como elemento geral da teoria do inadimplemento que subsidia a percepção da realidade obrigacional para além do mero prestar.

Do ponto de vista prático, esse enfoque permite que o resguardo 
dos bens patrimoniais e extrapatrimoniais dos contratantes deixe de pertencer ao instituto autônomo da violação positiva do contrato e passe a integrar a estrutura do inadimplemento absoluto e da mora. Dessa forma, a tutela dos interesses obrigacionais à proteção, hoje baseada exclusivamente na boa-fé objetiva e em interpretações analógicas, poderá contar com o arcabouço normativo tradicionalmente aplicado na defesa dos interesses obrigacionais à prestação. Exemplificativamente, o descumprimento dos deveres de proteção poderá ensejar, conforme o caso, as repercussões já assentadas para o caso de inobservância dos deveres de prestação (perdas e danos, juros, atualização monetária, honorários de advogado, oponibilidade de exceção do contrato não cumprido, faculdade de resolução contratual etc.).

De certo modo, é possível resgatar, no direito brasileiro atual, as críticas elaboradas por Heinrich Stoll contra a teorização original de Hermann Staub. Não no viés de afastar a problematização introduzida pela violação positiva do contrato - que revelou incontestável valor desde sua origem -, mas sim no sentido de questionar a necessidade da violação positiva do contrato enquanto uma terceira espécie de inadimplemento em face de uma compreensão expandida do fenômeno obrigacional.

\section{REFERÊNCIAS}

AZEVEDO, Antônio Junqueira. Insuficiências, deficiências e desatualização do projeto de Código Civil na questão da boafé objetiva nos contratos. Disponível em: <http://ead2.fgv.br/ls5/ centro_rec/docs/Insuficiencias_deficiencias_e_desatualizacao.pdf $>$. Acesso em: 5 jul. 2017.

AZULAY, Fortunato. Do inadimplemento antecipado do contrato.

SCIENTIA IURIS, Londrina, v.22, n.1, p.258-282, mar.2018 DOI: 110.5433/2178-8189.2018v22n1p258 
Rio de Janeiro: Brasília, 1977.

BRASIL. Lei $\mathbf{n}^{\mathbf{0}} \mathbf{1 0 . 4 0 6}$, de 10 de janeiro de 2002. Institui o Código Civil. Disponível em: <http://www.planalto.gov.br/CCivil_03/ leis/2002/L10406.htm>. Acesso em: 5 jul. 2017.

BUSSATTA, Eduardo Luiz. Resolução dos contratos e teoria do adimplemento substancial. São Paulo: Saraiva, 2007.

CORDEIRO, António Manuel da Rocha e Menezes. Da boa fé no direito civil. Coimbra: Almedina, 2015.

COSTA, Mário Júlio de Almeida. Direito das obrigações. 12. ed. Coimbra: Almedina, 2016.

CUNHA, Lavínia Cavalcanti Lima. Cumprimento defeituoso: conceito, pressupostos e comparativo com a violação positiva do contrato. Revista Magister de Direito Empresarial, Concorrencial e do Consumidor, Porto Alegre, ano 10, n. 57, p. 81-95, jun./jul. 2014.

FARIAS, Cristiano Chaves de; ROSENVALD, Nelson. Curso de direito civil. 9. ed. São Paulo: Atlas, 2015.

GAMA, Guilherme Calmon Nogueira da; ARAUJO, Karina Gomes Alves Fernandes de. A violação positiva do contrato nas relações paritárias. Revista Forense, Rio de Janeiro, ano 107, v. 414, p. 125149, jul./dez. 2011.

GONÇALVES, Carlos Roberto. Direito civil brasileiro. 11. ed. São Paulo: Saraiva, 2014.

HAICAL, Gustavo Luís da Cruz. O inadimplemento pelo descumprimento exclusivo de dever lateral advindo da boa-fé objetiva. Revista dos Tribunais, São Paulo, ano 99, v. 900, p. 45-84, out. 2010.

LARENZ, Karl. Derecho de obligaciones. Tradução de Jaime Santos 
Briz. Madrid: Editorial Revista de Derecho Privado, 1958.

LEITÃO, Luis Manuel Teles de Menezes. Direito das obrigações. 9. ed. Coimbra: Almedina, 2010.

MARTINS-COSTA, Judith. A boa-fé no direito privado: critérios para a sua aplicação. São Paulo: Marcial Pons, 2015.

MARTINS-COSTA, Judith. Comentários ao novo código civil. 2. ed. Rio de Janeiro: Forense, 2006.

MINAS GERAIS. Tribunal de Justiça. Apelação no

1.0707.08.167561-3/001. Apelante: Unimed Paulistana Soc. Coop.

Trab. Médico. Apelado: Unimed Varginha - Cooperativa de Trabalho Médico. Relator: Desembargador Pereira da Silva. Belo Horizonte, 2 de agosto de 2011. Disponível em: <http://www5.tjmg.jus.br/ jurisprudencia/formEspelhoAcordao.do $>$. Acesso em: 2 jul. 2017.

PEREIRA, Caio Mário da Silva. Instituições de direito civil. 29. ed. Rio de Janeiro: Forense, 2017.

PEREIRA, Fabio Queiroz. O direito comercial e a formação histórica do princípio da boa-fé objetiva. Scientia Iuris, Londrina, v. 17, n. 2, p. 9-28, dez. 2013.

PEREIRA, Fabio Queiroz. O ressarcimento do dano pré-contratual: interesse negativo e interesse positivo. São Paulo: Almedina, 2017.

MIRANDA, Francisco Cavalcanti Pontes. Tratado de direito privado. 3. ed. Rio de Janeiro: Borsoi, 1971.

RIO GRANDE DO SUL. Tribunal de Justiça. Recurso Inominado $\mathbf{n}^{0}$ 71006750467. Recorrente: Clara Nicolassia de Campos Oldani. Recorrido: Banco Itaú. Relator Juiz Roberto Behrensdorf Gomes da Silva. Porto Alegre, 7 de junho de 2017. Disponível em: $<$ https:// www.tjrs.jus.br/site/jurisprudencia/>. Acesso em: 2 jul. 2017. 
SÃO PAULO. Tribunal de Justiça. Apelação no 1049600-

35.2016.8.26.0576. Apelante: Patrícia da Silva Bernardes. Apelada: MRV Engenharia e Participações S/A. Relator: Desembargador Francisco Loureiro. São Paulo, 17 de maio de 2017. Disponível em: $<$ https://esaj.tjsp.jus.br/cjsg/consultaCompleta.do $>$. Acesso em: 2 jul. 2017.

SCHREIBER, Anderson. A tríplice transformação do adimplemento: adimplemento substancial, inadimplemento antecipado e outras figuras. Revista Trimestral de Direito Civil, Rio de Janeiro, v. 8, n. 32, p. 3-27, out. 2007.

SILVA, Clóvis V. Couto. A obrigação como processo. Rio de Janeiro: FGV, 2006.

SILVA, Jorge Cesa Ferreira da. A boa-fé e a violação positiva do contrato. Rio de Janeiro: Renovar, 2002.

STEINER, Renata C. Descumprimento contratual: boa-fé e violação positiva do contrato. São Paulo: Quartier Latin, 2014.

Como citar: ANDRADE, Daniel de Pádua; PEREIRA, Fabio Queiroz. Revisitando o papel da violação positiva do contrato na teoria do inadimplemento. Scientia Iuris, Londrina, v. 22, n. 1, p.258-282, mar. 2018. DOI: $10.5433 / 2178-8189.2018 v 22 n 1 p 258$. ISSN: $2178-8189$

Recebido em: 19/08/2017

Aprovado em: 22/02/2018 